\title{
Editorial 57
}

\author{
Eric Scerri ${ }^{1}$
}

Published online: 19 August 2017

(c) Springer Science+Business Media B.V. 2017

I write this latest editorial after returning home to Los Angeles following a European trip that began at our most recent society meeting, which was wonderfully organized in Paris by Jean Pierre Llored. As I mentioned in my own lecture in Paris, this was our 21st consecutive meeting that clearly signals the society's officially 'coming of age'.

The current issue of the journal consists mainly of the second part of a special issue devoted to some of the papers that were presented at the 20th annual meeting held in Boca Raton, Florida. ${ }^{1}$ One of the organizers, Marina Banchetti-Robino has also served as the editor of this special issue and I will leave it to her to introduce the articles in the following guest editorial. ${ }^{2}$

In addition it is my great pleasure to announce that Marina has agreed to act as the new book review editor for the journal. Please consider contacting her if you are interested in reviewing any relevant recent books on historical or philosophical aspects of chemistry.

Finally, the issue closes with a varia article by Geoffrey Blumenthal and James Ladyman from the University of Bristol and a book review written by the philosopher and Kuhn scholar, Brad Wray. By a further coincidence Geoffrey Blumenthal will be the organizer of the 22nd ISPC conference to be held in the summer of 2018, the details of which will be available soon on the ISPC website. ${ }^{3}$

Finally I would like to mention the recent publication of a book that may be of interest to readers of this journal, namely Hinne Hettema's, The Union of Chemistry and Physics. ${ }^{4}$

\footnotetext{
1 The first part of the special issue was published in volume 19, issue number 1 .

2 The other organizer was Marina's husband, Clevis Hedley.

3 https://sites.google.com/site/socphilchem/.

${ }^{4}$ H. Hettema, The Union of Chemistry and Physics, Springer, Berlin, 2017.
}

Eric Scerri

scerri@chem.ucla.edu

1 Department of Chemistry and Biochemistry, UCLA, Los Angeles, CA 90095, USA 